Franceschelli M. O'Brien M. (2015) 'Being Modern and Modest': South Asian Young British Muslims Negotiating influences on their identities. Ethnicities (October 2015, Forthcoming).

This is not the final draft.

\title{
'Being Modern and Modest': \\ South Asian Young British Muslims Negotiating Multiple Influences on their Identity
}

\begin{abstract}
With the rise of multiculturalism in Britain the visibility of religion, in particular Islam has increased. This growing religious diversity has created new contexts and affected young people's identity and transitions to adulthood. This article applies and extends Bourdieu's theory of habitus and social fields to a new area which is the study of how South Asian young Muslims living in England negotiate between the Muslim and British aspects of their identity. The set of individual dispositions (habitus), which originates in the family field under the influence of South Asian cultures and Islam, changes and is transformed when it comes into contact with non-Islamic fields. As with the concept of habitus, identity involves reconciling individual dispositions and structural conditions. Based on qualitative insights emerging from 25 semi-structured interviews with South Asian young Muslims, the article presents different strategies of identity negotiations exemplifying the constant and complex interplay between individual agency and the social world.
\end{abstract}

Keywords: Bourdieu; identity; habitus; Islam; South Asian Muslims; social field; young people; typologies. 


\section{Introduction}

Moral panic about Islam has been rising as a consequence of events such as 9/11, the 2005 London bombings and the most recent attack on the French satirical magazine 'Charlie Hebdo'. Data from the 2011 British Census indicate that the Muslim population in England and Wales has reached 2.7 million, 4.8 per cent of the overall British population and an increase of 1.1 million compared to the 2001 Census. The implications for young people's identity and transitions to adulthood are multiple. Young Muslims living in western countries have been increasingly under the spotlight perceived by the public and described by the media as 'alienated, deviant, underachieving, and potential terrorists' (Dwyer, Shah, \& Sanghera 2008, 117) and also 'militant and aggressive and intrinsically fundamentalist' (Archer 2001, 81). Just after the London bombings a report highlighted how young British Muslims have been 'overshadowed by misconceptions and the need to create a story' (Peace Direct 2006: 4). Much of the debate on young Muslims and identity has focused on how different boundaries of identity are integrated into new hybridities (Hall, 1992). This existing work has mostly conceptualised identity as 'identities' thus multiple and plural. At the same time, these scholars have put effort in discrediting those who have asserted that having multiple identities may call into question the loyalty to a unique sense of national identity and belonging.

Drawing on qualitative interviews with young British Muslims from South Asian backgrounds (Bangladeshi, Indian and Pakistani), this article explores how they negotiate between the Muslim and British aspects of their identity. The analysis identifies three main strategies of negotiations, 'combining, converging and diverging', which were employed by young people to reconcile influences coming from different socio-cultural contexts. The idea of 'being modern and modest' summarises the effort of bringing together different identity orientations originating between the family and the wider British society. In making sense of these findings, we provide a new application of Bourdieu's theory of habitus and social field to the study of young British Muslims' identity. In the 
context of an increasingly multi-faith British society, the article contributes to the debate about multiculturalism by introducing the micro-level of identity into the macro-level policy discussion about reconciling equality while respecting diversity (Modood, 2010).

The article first reviews empirical and theoretical literature relevant to the study of young British Muslims' identity. It then describes the main elements of the data collection and analysis. The subsequent sections of the paper report findings from qualitative interviews with young people. Finally, conclusions reflect on the empirical and theoretical contributions of the paper.

\section{Understanding identity negotiations}

Previous research on young British Muslims has pointed to their multiple identities with references to 'fluidity and hybridity' as a 'fusion of cultural influences' which are not exclusively Muslim or British (Dwyer 2000, 483). Hall (1992) argues that diasporic populations develop identities that encompass national boundaries and fixed categories. These processes involve inhabiting and negotiating distinct identifications at the same time. In this sense, diasporic identities are associated with the idea of 'hybridities' reflecting new forms of belonging, what Brah (1996) describes as 'British Asianness'. These hybridities also inform the debate about multiculturalism, which explores how 'dominant and subordinate cultures are synthesised' (Modood et al., 1997, p.358).

Hybrid and multiple identities are also reconfigured by gender, class or religion. In a study of British Pakistani boys, Dwyer et al. (2008) found that class affected the extent and motivations of their religious identity and masculinities. Other research suggests (Ramji, 2007) gendered differences in the mobilization of Islam: boys were adopting Islam to legitimise their role as providers, whilst girls used Islam to challenge the conventional understanding of their roles in the domestic sphere. Analysis of post-16 educational choices of Muslim girls (Archer, 2002) shows how female respondents rejected the notions of gendered restricted choices and argued that families supported and valued their education. Religion was also adopted to reconcile multiple and complex identities. 
Zine (2001) suggests that young Muslims in Canada were negotiating identities by adopting their religious identification as the anchor of their sense of self and as a form of resistance to the social pressures affecting their distinct lifestyles. These studies about young Muslims highlight some specific aspects of their transitions to adulthood influenced by their religion and culture. However, they also reflect more general societal trends affecting young people and intergenerational relations (Furlong and Cartmel, 2006; Jones, 2009).

Muslim young people also provide an important context for understanding identity development as the result of negotiating inner and outer factors (Weigert \& Teitge, 1986; Cote and Levine, 2002). This dichotomy mirrors the sociological question of how subjectivity and objectivity can be reconciled, which is central to the social theory of Pierre Bourdieu. In seeking to understand further the mechanisms underlying the development of individual identity and their interplay with the wider social world, we draw from Bourdieu's concepts of habitus and social field and particularly their reciprocal interplay.

\section{Habitus, social fields and identity}

Bourdieu defines habitus as 'individual dispositions' or predisposed ways of acting in a certain manner. He argues that these dispositions are placed inside individuals, but originate externally through interaction (Bourdieu, 1990). According to Bourdieu, habitus is complementary to the notion of 'social field', which is the social space where the habitus operates. The fields are characterised by hierarchical relations of power where individuals are in constant struggle in the pursuit of desirable resources (Bourdieu and Wacquant, 1992). Bourdieu describes the field through a metaphor: if we think about the social world as a game, the field is 'the feel for the game'. In other words, the field is the body of regulating norms, which set out the reciprocal relations and positioning of the players or agents (Bourdieu, 1990). Therefore, the earlier the players enter the game the more the rules become tacitly granted and therefore easier to adapt to. Bourdieu 
describes the relations between the habitus and the field as 'a miraculous encounter' between incorporated and objectified histories. The habitus internalises elements from the social fields and then reflects them externally through subjective practices such as individual outlook, gestures, and mannerisms, which Bourdieu considers elements of a wider lifestyle. He defines lifestyle as a 'unitary set of distinctive preferences socially produced in the different fields' (Bourdieu, 1984, p.169) and argues that it embodies the way individual's habitus is externalised via subjective practices.

Bourdieu's assumption that habitus and field are naturally subject to an ontological complicity, where dispositions adapt to social situations leading to their reciprocal reproduction, has been criticised. In the 'Plural Actor' Lahire (2011) argues that the relation between habitus and fields is more complex than Bourdieu initially anticipated: the many situations in which individuals are 'transplanted' from one field to another, such as migration or social mobility, lead to 'maladjusted' and 'out of place' individuals. These individuals have to face 'cultural apprenticeship, knowledge and social relations that are quite foreign to their original milieu' (Lahire, 2011, X).

Baxter and Britton (2001) adopted the 'habitus and fields' framework to study the identity negotiation of working class mature students accessing higher education later in life. In so doing, they developed the idea of 'habitus dislocation', which explains the feelings of inadequacy and displacement attached to a habitus coming into contact with fields different from where it firstly originated:

'Such experiences tend to produce a habitus divided against itself, in constant negotiation with itself and with its ambivalence, and therefore doomed to a kind of duplication, to a double perception of self, to successive allegiances and multiple identities' (Bourdieu et al., 1999 , 511 in Baxter and Britton, 2001, 99).

This idea of 'habitus dislocation' has been applied extensively in research on social mobility particularly looking at changes in the working class habitus when accessing the social field of higher education (Reay, 2009; Ingram, 2011; Lehman 2009; 2013). Studies about British Muslims in higher education also highlight the challenges connected to accessing new, unknown and non-Islamic social 
fields. However, the nature of these challenges is different from a solely class-based perspective and it involves complex narratives against consolidated stereotyping discourses such as those framing Muslim women (Ahmad, 2012). In the context of the migrants' habitus, Noble (2013) uses the idea of an 'ethnicised habitus' to explain the sense of difference attached to being part of the wider society of the country of destination as well as of one diasporic community.

There have been a number of criticisms of the concept of habitus dislocation. Bennett (2007) argues that 'habitus dislocation' is an underdeveloped appendix within Bourdieu's general theory leading to an inner contradiction. According to Bennett (2007), Bourdieu conceptualised habitus as a 'unifying principle' and a unitary concept that brings together those who come from similar conditions. In so doing, Bourdieu only allowed for the possibility of a less systematic and more dynamic habitus in fragmented passages of his theory. Noble (2013) applies Bennett's criticism of Bourdieu's unitary habitus, to the context of migration and claims that habitus is incapable of explaining the complexity of migrants' identities. He also suggests a shift from the idea of social field considered as being 'too macro' and 'one dimensional' (Noble, 2013, 354) to the 'micro-sociological language of settings'. In this article we adopt the idea that 'negotiating identities' uncovers the process of habitus operating in multiple social fields different to the domestic field where it firstly originated.

How are habitus and social fields related to identity? Identity is a contested concept in sociology to the point that its own use and effectiveness as an analytical tool has been questioned (Brubaker and Cooper, 2000). Brubaker and Cooper (2000) argue that identity has become too much of a unitary entity, unable to incorporate the 'unstable, multiple, fluctuating and fragmented nature of the contemporary self' (Brubaker and Cooper, 2000, p.8). This point can be related to Bennett's (2007) and Lahire (2013) critiques of Bourdieu's unitary habitus.

To progress with our empirical study, we needed a working definition of identity which took all these considerations into account. Regarding identity as a process, rather than a static category (ethnicity, 
nationality etc.) offers the flexibility that Brubaker and Cooper (2000) were seeking. In this way we sought to explore whether identity functions in a similar way to the habitus as they both result from the processes by which individuals internalise and reproduce elements of the social world. Both concepts also involve negotiating individual dispositions with cultural and national contexts. Therefore identity, like habitus, is conceived as the body of subjective orientations, which are assimilated by the individual in the social fields under the influence of structural conditions, and are then internalised to reflect subjective values, beliefs, tastes and practices (Franceschelli and O'Brien, 2014).

\section{Methodology}

This article draws on 25 semi-structured interviews conducted with South Asian young British Muslims aged 14-19 years in different regions of England. Three secondary schools in London and one College in Oldham supported us with the initial recruitment, but the final sample required a combination of snowballing techniques to improve its diversity. Most of the young people (12 girls, 13 boys) were second-generation UK born (except for two) from British Bangladeshi (10), British Pakistani (8) and British Indian (7) ethnic backgrounds. Based on parental employment status and qualifications, 17 young people were classified as from a working class background, whilst the remaining eight were from a middle-class background. In the reporting of findings all names were changed for confidentiality purposes.

The interviews covered different aspects of young people's identity from self-descriptions, to everyday activities, interests, beliefs, sense of belonging, social lives and aspirations. To support data elicitation and prioritise young people's perspectives we applied visual methods in the form of photographs taken by young respondents. Young people were asked prior to the interview to take some photographs of anything they felt was relevant to their identity. In the analysis, the photographs were used in combination with the text they contributed to produce and support the 
construction of analytical categories and ultimately the typologies. They were grouped thematically into: self-portraits and family members; friends; Islam; places; objects; and music.

The interviews were recorded with the participants' consent and the data analysis was carried out with NVIVO software using thematic analysis (Aronson, 1994). The development of typologies drew from three key steps: first, the discussion about the photographs generated preliminary accounts about social relations, personal interests and everyday activities; second, these accounts were brought together into wider themes - 'strategies of negotiation' - describing the processes used by young people to reconcile different influences, for instance their interest in American rap and Islam. Strategies of identity negotiation were then grouped into three overarching thematic areas, or 'typologies'.

Importantly, the positioning of the researcher, a white European woman, varied through the development of the study and involved considering the implications of an outsider accessing the studied communities (Haw, 1996; Becher, 2008). During the course of the fieldwork, the initial feeling of outsiderness was replaced by an increasing understanding of the families' cultural norms and religious values. From the young participants' point of view, there was a sense that the researcher being external to their community could provide more neutral perspectives, while her non-British identity created a sense of sharing based on 'being a minority or a migrant'.

\section{Negotiating British and Muslim aspects of identities: combining, converging and diverging}

In the article we set out the notion of the 'British aspect of identity' beyond the idea of nationality, citizenship or country of birth. Rather, our conceptualisation has been driven by young people's own interpretations. British identity came to signify different things in the context of the interview: for some young people being British was mostly about having access to opportunities, particularly education. For others it meant being able to overcome certain restrictions imposed on their social life 
by their parents, and was associated with the freedom of going out or drinking alcohol. Negotiating aspects of identity involved a polarisation between the non-Muslim British society and the domestic field of family. Within British society, young people come into close contact with the influences of the global youth culture, affecting their clothing, musical tastes and lifestyles. The domestic field of family is the main space where young people learn about Islam and South Asian cultures. Young respondents prioritised different aspects of their religious identity: from just believing, to practicing and praying. Islam was also a legacy and source of moral values informing behaviours.

British and Muslim identities were also constructed in relation to the Islamist attacks and the consequent debate about the loyalty of Muslims to the West. Young people's accounts followed a very similar line of argument: there was the need to reinforce the inner message of Islam while strongly condemning any violence carried out in its name:

\footnotetext{
I'm a Muslim and sometimes when I hear people (...) how they stereotype us and they think we're all terrorists. I do feel it's wrong and I do get hurt by it. There are particular people, particular Muslims that call themselves Muslims but ain't doing what is the way of life in Islam. What they're doing is wrong. In our religion Allah said that taking the life of an innocent person is not right (...) They're the wrong Muslims. They think if they do this stuff they are promised heaven but they're doing the wrong thing' (Ali, 16 years old, British Bangladeshi)
}

Rather than focusing on identity as self-definition and meaning of different categories (Hopkins, 2007) we explore the processes by which young people come to describe their identity. Three typologies were identified from the conversations with young people: 'combining, converging and diverging'.

\section{'All together they are me': combining influences coming from different social fields}

'Combining' different influences on identity is the overarching strategy employed by young people in the study to bring together dispositions emerging in different social fields, such as the domestic field of family and the public field of other social relationships. One approach adopted by young people to 
combine dimensions of identity and habitus was singling out the contribution that each aspect gave to their individual sense of self. The reconciliation of these different orientations informed the habitus as Omar's account 'all together they are me' illustrates. For Omar national, ethnic, and religious dispositions had different, but equally relevant functions, which impacted on his everyday life and affected his value system and sense of belonging:

' (...) For me Muslim relates to sort of religion so it is Islam so it's following the beliefs and as I've said it's the moral beliefs of what makes you a good individual and the religion crafts you to be the best individual that you can be. (...) Then being Pakistani is a sense of identity as you say it's my origin it's my it's where my family come from: I wasn't born there but by going back there I've found my roots and where my family have got all their views from our history. (...) Being British I was born and raised here it's given me all the opportunities I had which I never would have in Pakistan. It's tough like being able to go on the universities, the ability to think freely which is I guess given me sort of much more wisdom than I might have had otherwise in Pakistan. (...) (Omar, 18 year old, British Pakistani)

Combining multiple dispositions increased the complexity of making transitions to adulthood by imposing specific challenges in terms of handling everyday commitments:

'There are many things going on at the same time, so sometimes in Ramadan after being at school all day I would come home and do my homework, so that was in some way like my British bit but then I would have to go to mosque for a couple of hours and pray and so that was like the Muslim bit and Indian bit. It all just merges into one. Like at school all of my friends know I go to mosque. I do this and that and I have loads of things going on at the same time'. (Yasmeen, 14 year old, British Indian)

Combining also involved prioritising one dimension of identity over the others. In these cases, Islam was most often the main unifying term:

'Yes. I'm Muslim first, that's my religion. That's who I want to be. I want to be a Muslim. Before being British I'm a Muslim all the time. If I'm living in this country I'm going to support Britain. If you're doing something unjust I'm not going to support it. I'm Muslim then the nationality comes afterwards. First there is you then nationality. Religion always comes first for me'. (Saleem, 18 year old, British Pakistani)

Despite the most general trend being the decline of young people's religiosity in contemporary western societies (Collins-Mayo \& Dandelion 2010), these findings suggest that religion was particularly relevant to the self-definition of young Muslim respondents. 'Combining accounts' 
reflect how different orientations coexist into a unitary entity, but also how they alter it and transform it. By negotiating these influences and dispositions young people seek to try and maintain their habitus (and identity) together. In this sense 'being British, Muslim or Pakistani' were dispositions and internal orientations within the same unitary but complex and multifaceted habitus.

\section{'Being modern and modest'}

Respondents used the terms 'modern and modest' to explain two different dispositions reflecting the influences of Islam and British culture. Girls in particular described parental dispositions, which developed in the South Asian cultural milieu, as 'modest and traditional'. Similar findings were evident in Becher's (2008) study of South Asian Muslims families. Modern, instead, was with the British lifestyle that both boys and girls apprehended while growing up in the UK. Clothing style was the indicator used particularly by the girls to explain what 'modern and modest' meant to them. It emerged that 'being modern' signified having a contemporary outlook and wearing western clothes such as jeans, dresses, leggings, t-shirts and tops. 'Being modest' was described as the justification behind the practice of covering up to reduce women's perceived sexual allure (Tarlo, 2010). By wearing the hijab, the headscarf used by Muslim women to cover their hair, with 'modern' clothes the girls combined 'modern and modest' dispositions. 'Being modern and modest' also involved wearing dresses with long-sleeved t-shirts and skinny jeans underneath, or long-sleeved tops with jeans while making sure that arms and legs were kept fully covered. In so doing the girls showed how clothing practices, emerging from different social fields, could coexist as part of a unitary habitus. Hania was concerned about merging modern and modest styles while remaining 'fashionable':

\footnotetext{
'Well I think you can be modern and wear the hijab still as long as you are modest and dress modestly (...) I mean I think being eighteen years old, late teens it is important to still be fashionable but still religious at the same time. It has been one of my toughest challenges yet because if I didn't wear my Hijab now I would still be seen as typical British dressing because of my jewellery and how I have accessorised everything and just putting the Hijab on it's still the same. Do you know what I mean? Because I still try to be fashionable as well as religious.' (Hania, 18 year old, British Bangladeshi)
} 
However, the dichotomy 'modern and modest' goes beyond mere clothing dispositions and reflects a perceived dualism between what was associated with western and secular and what was considered traditional and religious (Archer, 2002). In Islam, modesty transcends the issue of what to wear and encompasses attitudes, behaviours and the relationships with others. For the young women making transitions to adulthood, modesty was an aspiration and a goal rather than something they felt they had already achieved. This view about a 'journey into modesty' as a route to self-improvement also discloses the complex transitions and negotiations of these young women:

'But I've seen some girls wearing like scarves and skinny jeans and yes they are covered up, but it still shows your figure and I used to do that but then I thought what's the point of me wearing the scarf then? But it's just a development I think when teenagers go through that phase of adjusting between two different cultures and making that transition into becoming more modest as you grow older, so yeah.' (Sakina, 18 years old, British Bangladeshi)

Although there was general agreement amongst the girls about the importance of modesty, they interpreted this concept in different ways, as reflected in their outlook and clothing. For some, the hijab was associated with modesty itself, even though some of them described other reasons to wear it. Mariam spoke about how the hijab had become an integral part of her habitus:

'Well to be honest when people see me with a Hijab they think I am religious but the reason I am wearing it now it's like I can't go outside the house. I was going to my next door neighbour's house and I had to put a cap on, I have to have something on my head. Identity, I feel like this is a part of me now'. (Mariam, 17 years old, British Bangladeshi)

In this study, none of the women wearing the hijab spoke about being forced to do so but rather they emphasised the idea of the hijab as 'choice' and as 'empowering' because it enabled them to be viewed beyond their appearance and with respect:

'It's nice knowing the fact that I will be judged for who I am personality-wise than oh look she looks hot, she looks good and stuff let me go and talk to her.' (Sakina)

Shifting between modest and modern clothing styles was also considered a matter of freedom and choice: 
'No I don't always wear (Asian clothes) them. Majority of the time I wear them at home, (...) but I also wear like jeans and stuff because that is a part of my identity as well. (...) I just like wearing what I want I know it is important to cover yourself and so I wear everything that covers and I just follow my own trend.' (Maria, 17 years old, British Pakistani)

These references to choice were used by female respondents to challenge stereotypes about Muslim women being oppressed. However, as Archer (2002) argues in her study of Muslim girls post-16 educational journeys, individual choices are socially situated and cannot always be understood outside the context and constraints of the fields where they originate. In this sense, 'being modern and modest' reflect the negotiation of dispositions, which have implications for the construction of gender identities.

\section{Islam, rap, class and aspirations}

Another aspect of combining influences on identity was visible through some of the boys' views on rap music. Young people explained that photographs of IPods and of pop and R\&B singers or rappers represented music, which was described as relevant to their identity and habitus. For some of them music was just leisure but for others it was more of a source of aspirations. A group of British Bangladeshi boys spoke extensively about the Black American rapper Lil Wayne who they said they had adopted as their role model. The Bangladeshi boys were from working class backgrounds: their parents were not educated, their mothers were out of work and the fathers were mostly in low skilled jobs. They were also living in social housing in a deprived area in Greater London. Other research has highlighted the important contribution of rap music and hip-hop for the construction of youth masculinities in the context of disadvantaged minority groups, particularly Black boys (Clay, 2003). The accounts of Bangladeshi boys about rap emerged from a discussion about pictures of Lil Wayne downloaded from the Internet and his music and videos were played during the interviews. Lil Wayne is known for his rebellious lifestyle. His videos contain sexual scenes, he raps about money and power and he has been in and out of jail because of drug-related crimes. However, the Bangladeshi boys explained how their passion for Lil Wayne did not affect their religious identity. 
How did they combine their role model Lil Wayne with their self-identification as Muslims? Their accounts suggest that Lil Wayne embodied a parable of success: someone from a disadvantaged background who broke down barriers and became famous worldwide. Therefore, rap music was presented as an alternative route to fulfil aspirations, achieve wealth and social mobility. Tahir exemplifies this way of thinking. In the account below he describes his personal journey and how he got involved with music to compensate for his failure in education:

'I got into music because in year nine I started a bad path. I started to blaze a lot, do weed, I used to bunk a lot, take drugs. That's why my education wasn't that good. (...) If I could, I would go back and I wouldn't mind being a lawyer. You need very good degrees, grades (...). That's when I started listening to music. I found it easier. Some things I really like and I won't get bored of it. Then I just made my own tracks. That's how it is. I just made music my career. I want to become a rapper (...). My heart's more into music. I don't see nothing else for me in the future other than music and become a rap artist. I'm really determined. My whole heart's in music. That's it'.

Combing opposite dispositions, such as those deriving from rap and Islam, also reflects the influences of class and disadvantage on opportunities and views of the future.

\section{'Converging': a strategy about understanding, accepting and sharing parental culture and Islam}

There were two different ways of combining aspects of identity: 'converging' and 'diverging'. These two sub-typologies reflect how habitus, which originated in the family field, changes and adapts when it accesses other social non-Muslim fields. We first consider 'converging'.

Some young people tended to combine influences on their identity by 'converging' toward the parental system of values. Young people who were converging were deeply critical of going out, drinking alcohol or smoking. They took photographs of their family and home and discussed how they aligned strongly with parental moral standards. However, in doing so, they did not conform passively to parental restrictions on their social lives, but rather they reflected on them and then assessed the benefits of following certain norms: 
'Maybe it's because l've been brought up like that, but I don't feel like I'm missing out on anything. I don't know how l'd think if I was brought up thinking drinking and smoking is fine. But at the moment even if Islam said you could smoke it ruins your health so I don't want to do it. Drinking you lose your mind you're not in your right senses. (...) I guess it's a lot about not doing things but if I did smoke and drink I don't think that would make my life better'. (Tania, 18 years old, British Indian)

The attitude favouring a contained social life involved criticism and condemnation of the 'going out' that was associated with drinking and taking drugs. This way of thinking was evident across different social classes and was shared by several young boys and girls in the study. The accounts from Omar, a Pakistani boy from a middle class background, illustrate how 'converging' involved levels of active construction. Omar elaborated justifications underlying the religious prohibition of drinking:

'The reason of drinking it's not said specifically drinking it said intoxication so then that's I think the reason such rules are made were because there's no way to control your inhibitions (...) all intoxications were banned because (...) you don't know what you're doing and you do something you'd regret and that's the reason it's banned in religion'.

In the case of Sakina, an 18 year old British Bangladeshi girl from a lower socio-economic background, the sense of sharing and continuity with parental values was reflected in her criticism of what she described as the 'British pub culture':

'Never no. I have never been interested in 'pub culture'. I mean... Because you've never done it, you don't really like it. I mean to be honest I walk past pubs and they stink! I don't mean to be offensive, but they really do. I don't really like the smell and then you see pictures and you see videos of people throwing up and acting so obscenely after a night out. And even though it's really funny and you have a great laugh, but then you think what does it say when the only way you can have fun is to forget about what you're doing and just to make a fool out of yourself really. I mean my friends we go out, I mean yesterday we had a party and we were dancing and everything. But we were sober and we were just high on happy and happiness and life really in general.'

The condemnation of the 'British pub culture' revealed how Sakina conformed to parental norms (Franceschelli and O'Brien, 2014). For her, converging was the result of her understanding that parents prohibited certain activities primarily to protect their children. Understanding this, led Sakina to ultimately agree with certain restrictions bringing about acceptance and respect:

'My dad was the one who started talking about values and systems and your morals and so he not only instilled Muslim morals in me, but his own morals as well. He instilled his own boundaries and his beliefs within us as well. So there's so many things like we 
questions too like "oh why can't we do this?", like this is not something specific to Islam, but this is to my family as in, you know, "why can't I go out with my friends?". And so basically what he was telling me was about protection. He told me that "this time of your life is where you're going to change as a person, with people you make friends with are going to have a huge impact on you, so you've got to be really really careful who you make friends with". So he was trying to make sure that I choose right who my friends are and also never forgetting who I am and where I come from'.

The link between protection and control involves a specific view of young people as under the threat of negative influences of society. Whether parental control and protection were exercised on both boys and girls they appeared to affect them differently. Parental gendered expectations perceive young women as the 'guardians' of the family's religious and cultural integrity (Dwyer, 2000). Boys instead are seen as the future providers and therefore are granted more freedom and independence.

The story of Ali, a 16 year old British Bangladeshi boy, reflects these gendered expectations in the context of his specific family field characterised by socio-economic disadvantage and by growing up only with his unemployed mother and younger sister. The absence of the father was an important factor which increased Ali's sense of responsibility:

'Yes. I'm the man of the house. I do the shopping with my mum. Help her out at home as well and help my sister study as well. Yes it is hard. It's fast paced and to get along you need someone to support you as well financially and emotionally. I haven't had no contact with my dad since then. That's it'.

Ali adopted the idea of 'willpower' to combine contrasting dispositions while converging toward his mother's moral standards:

'Willpower is something that's human behaviour. It's not made up. When I was in primary school and we were doing this campaigning on stop smoking and we had to create a leaflet and the book was called "Willpower" and that's where it got it from (...)'.

Amongst other young people, Ali demonstrated a higher level of complexity because he had to negotiate family responsibilities with his social life. He explained that his friends drank alcohol, used drugs and were part of a local gang. Though, he pointed out that relying on his personal willpower 
enabled him to move away from a situation when things turned against his beliefs such as not smoking or drinking when others did so:

'It's not difficult (not to drink or smoke when others do). It's all to do with willpower. You can do it. Anyone can do it. It's possible. Anything's possible. (...) It's all on your willpower and what you think is right. If you focus on one thing and steer on the right path, you don't have to think about other things.'

In this account, Ali reflected in his own terms on a very crucial topic of Islam: The Surah Al Fatihah, the opening verses of The Qur'an. This passage of The Qur'an introduces the everyday Muslim prayers and makes reference to the idea of the 'right path':

'Lord of the Day of Judgement.

It is You we worship, and upon You we call for help.

Guide us to the straight path,

The path of those upon whom Your grace abounds, Nor those upon whom anger falls,

Nor those who are lost'. (Al Fatiha, The Qur'an)

'Converging' also had an important impact on young people's aspirations. As noted by Archer (2002), South Asian cultures informed the types of professional careers, such medicine, law, pharmacy, dentistry or generally self-employment, highly appreciated by parents. For instance, Zahra, who was interested in science decided to go for dentistry as it felt like 'a more practical approach' while Tania gave up on her idea of doing bioscience and was prepared to follow the parents' advice and doing physiotherapy.

Young people who combined influences from the social fields by converging toward their parents' views reproduced their family field but not in a neutral and unchanged manner. Rather, their experiences were filtered by their everyday interactions and by growing up in non-Muslim British society.

\section{'Diverging' from parental values: dealing with going out, drinking and believing}

In order to combine the influences affecting their identity some young people ended up diverging from their parents and distancing themselves from the family's values. By 'diverging' young people 
challenged parental impositions on their social lives and relationships, and got involved with 'unIslamic practices'. The interview accounts suggest that some young people, particularly boys, were keen on going out, drinking alcohol, smoking or taking drugs. To justify the contradictions deriving from conducting a social life which challenged the moral standards set out by both South Asian cultures and Islam, these young people developed discourses which fed into 'diverging strategies'.

These accounts were more relevant amongst some young boys rather than the girls, who did not show the same level of engagement with challenging their parents. Gendered expectations on women, as the guardians of the family's reputation, had affected some of the girls' socialisation in the family field and kept them away from an interest in clubbing or drinking. Girls tended to be more controlled by parents. They were going out less often and mostly during the daytime, and they had to come home earlier than boys. However, as with young people who were converging, the girls showed an understanding of their parents' concerns rather than passive acceptance.

Going out was one of the most common arenas for confrontation between young people and their parents. Wajid, an 18 year old British Pakistani boy from a working class background, described his conflictual relationship with his parents:

'It's mostly about timings and like what I do when I go out because I go out with friends but my parents see it as a bad thing, like that I shouldn't stay out that late. (...)

It's always confronting them to be honest, it's always like that confrontation thing. It's always like mainly arguments but we have like come to an agreement. We sometimes do agree on things like let's say I come home late and I say "I am eighteen now" and then I ask for the independence. I say "can I have that extra hour or two". It is not going to be like an everyday thing but I ask for a bit more and if they say yeah then that's fine but if they say no then I try asking again and we argue'.

Wajid spoke about his desire for more independence of the kind he saw in the lives of his nonMuslim friends. 'Diverging' often took the form of negotiating choice and constraint, freedom and restrictions. In order to resolve this conflict some young people created a divide between private/family and public/social fields: 
'To be honest there is obviously a contrast, so my parents it's more a different background to outside and so what I try to do is keep them separate. If I go out I don't have that Pakistani culture. I have the whole do what I want but at home it is more that thing of because I speak Pakistani to my parents. It is always that culture mix I reckon'. (Wajid)

Drinking and taking drugs were attached to the ways some of the young respondents socialised and spent time with their friends. These practices and lifestyles are very general parental concerns. However, they were even more difficult for young people to reconcile with Islam and South Asian cultures, which both set very strict moral standards and emphasise a sense of control. Therefore 'diverging' involved a number of coping strategies comprising justifications to reconcile Muslim identity with non-Muslim practices. These compromises involved explanations and justifications such as 'no one is perfect', 'this life is a test', 'everybody makes mistakes', 'God will forgive'. In order to justify his drinking and smoking, a young boy argued that 'being part of $21^{\text {st }}$ century' makes certain practices amongst young people unavoidable.

There were emotional consequences attached to diverging from parents' views. Another young boy expressed a sense of guilt for behaving against what his parents would expect. He felt this would lead him eventually to becoming less religious:

'You say to yourself 'I'm not going to do it, my religion does not allow me to do that'. But when you see someone doing it, it just goes out your head and you go do it. It's quite hard. Yes I feel guilty then I pray sometimes and ask for forgiveness.

So, how do you see your future in terms of your religion?

Probably going on the other side. So being less religious you know'.

Amongst those who diverged, clothing and hairstyles were other arenas of intergenerational confrontation. As reflected in the photographs of some young boys clothing and hairstyle dispositions illustrate the importance of physical appearance for belonging to a peer group and related to Bourdieu's idea that habitus is imprinted in the body of an individual. Clothes, such as oversized baggy trousers, big unlaced trainers, chain necklace as well as haircuts were a means of bonding and indicated the sharing of a lifestyle and being part of a group. However, this type of 
outlook was highly criticised by Muslim parents who did not allow their children in the house unless they 'changed into normal clothes'. Some young boys spoke about how much their parents disliked their haircuts:

'I could say stuff like my hair for instance, it's mainly to do with culture in Bengali people. Culture like they could say to my dad I saw your son the other day in the road, what's going on with his hair? Obviously my dad will feel ashamed of that and would have a go at me for that'. (Davar)

Finally, by combining, converging and diverging young people expressed the changes that their habitus undergoes when accessing new and multiple fields.

\section{Conclusions}

The events of 9/11, London bombings and the most recent attack to Charlie Hebdo in Paris (2015) have raised questions about contemporary models of social integration, not least for Muslim young people. In this context, the article has focused on the experiences of South Asian young Muslim girls and boys living in different areas of England and, it has explored how this specific group of young people negotiate their Muslim identity with the influences from the non-Muslim British society.

The emerging typologies 'combining, converging and diverging' illustrate complex transitions to adulthood detailing how young people negotiated agency and structure. Therefore, in Bourdieu's terms, they exemplify how their individual habitus endured the influences coming from multiple, and at times, contrasting social fields. The typologies also provide insights into how young people adopted lifestyles and outlooks that developed between different fields, as the idea of combining 'being modern and modest' suggests. The influences of gender and class were visible within each typology: 'combining' includes boys and girls from different socio-economic backgrounds; 'converging' involved accounts of boys from higher economic backgrounds and girls from both middle and working class backgrounds. 'Diverging' entailed a group of young boys from lower socioeconomic backgrounds. These typologies also reflect more general trends of youth identity transitions and intergenerational relations. 'Converging and diverging' are in line with wider analysis, 
which describes the relations between parents and young people in terms of conflict or solidarity (Bergson, et al 2002; Szydlik, 2008).

Bourdieu's concepts of habitus and field underlay the construction of the typologies and the definition of identity. In this way, the article has provided a new application of Bourdieu's theory, which is extended to the study of young British Muslims' identity. Both habitus and identity are contested notions because of their tendency to amalgamate and unify individual dispositions into single entities running the risk of reducing their complexities. Lahire (2011) and Bennett (2007) argue that the habitus is made of multiple and contradictory dispositions and it is therefore more dynamic than what Bourdieu originally anticipated. However, together with taking into account the complexity of the habitus, it is important to consider the implications deriving from the plurality of social fields where the habitus operates. Combining, converging and diverging incorporate these complex negotiations and reflect the effort of making sense of different influences and dispositions, while keeping identity and habitus together. In this sense, the typologies connect the macro-level question of multiculturalism, namely how equality can be promoted alongside respect for diversity (Modood, 2010), with the micro-level processes of identity.

Another criticism attached to the concept of habitus revolves around its inadequacy to explain mobility and change leading to claims of social determinism (Jenkins, 2002). However, the different typologies of identity/habitus negotiations also express a sense of agency as they incorporate levels of active identity construction. This study suggests that young people were not passively reproducing their family field through conforming to their parents' values and moral standards. Rather they were reflecting on and making sense of the restrictions imposed on them by their parents.

Ultimately, the research has provided direct accounts about the values, beliefs and priorities that are relevant to South Asian Muslim young people in England. These insights will help inform 
multicultural theory and policy (Modood, 2007; Parekh, 2000), and improve understanding of Muslim young people who are often stereotyped and perceived as 'hard to integrate'. 


\section{References}

Ahmad F (2012) Growing up under the lockdown or educational pioneers. Challenging stereotypes of British Muslim women in higher education in Ahmad F and Seddon MS (eds) Muslim youth: challenges, opportunities and expectations. London: Continuum.

Archer L (2001) Muslim brothers, black lads, traditional Asians: British Muslim young men's constructions of 'race', religion and masculinity. Feminism and Psychology 11(1): 79-105.

Archer L (2002) Change, Culture and Tradition: British Muslim pupils talk about Muslim girls' post-16 'choices'. Race Ethnicity and Education 5(4): 359 - 376.

Aronson J (1994) A Pragmatic View of Thematic Analysis. The Qualitative Report 2(1): 1-3.

Baxter A and Britton C (2011) Risk, identity and change: becoming a mature student. International Studies in Sociology of Education 11 (1): 87-104.

Becher H (2008) Family Practices in South Asian Muslim Families. Basingstoke: Palgrave Macmillan.

Bennet T (2007) Habitus Clivé: Aesthetics and Politics in the Work of Pierre Bourdieu. New Literary History 38: 201-228.

Bengtson.V. L., Giarrusso,R., Mabry, J. B. and Silverstein,M. (2002). Solidarity, Conflict and Ambivilence: complementary or competing perspectives on intergenrational relations? Jounral of MarriageandFamily, 64: 568-576.

Bourdieu P (1984) Distinction. London \& New York: Routledge.

Bourdieu P (1990) The Logic of Practice. Stanford: Stanford University Press.

Brah A (1996) Cartographies of Diaspora, contesting identities. London \& New York: Routledge.

Brubaker R and Cooper F (2000) Beyond identity. Theory and Society 29: 1-47.

Collins-Mayo, S. and P. Dandelion, eds. (2010) Religion and youth. Farnham Surrey and Burlington USA: Ashgate.

Coté JE and Levine CG (2002) Identity Formation, Agency and Culture. Mahwah: Lawrence Erlbaum Associates.

Clay A. (2003) Keepin' it Real: Black Youth, Hip-Hop Culture, and Black Identity. American Behaviural Scientist, 46 (10): 1346-1358. 
Dwyer C, Shah B and Sanghera G (2008) From cricket lover to terror suspect - challenging representations of young British Muslim men. Gender, Place \& Culture 15(2): 117-136.

Dwyer C (2000) Negotiating diasporic identities: Young British South Asian Muslim women. Women's Studies International Forum 23(4), 475-486.

Franceschelli M and O'Brien M (2014) 'Islamic Capital' and Family Life: The Role of Islam in Parenting. Sociology 48(6): 1190-1206.

Hall S (1992) The question of cultural identity in Hall S et al. (eds) Modernity and its future, Cambridge: Polity Press 273-325.

Haw K F (1996) Exploring the Educational Experiences of Muslim Girls: tales told to tourists: should the white researcher stay at home? British Educational Research Journal 22(3): 318-330.

Hopkins P (2007) 'Blue Squares', 'Proper Muslims ad Transnational Networks: Narratives of National and Religious Identities Amongst Young Muslim men Living in Scotland. Ethnicities 7(1): 61-81.

Ingram N (2011) Within School and Beyond the Gate: the Complexities of Being Educationally Successful and Working Class. Sociology 45(2): 287-302.

Lahire B (2011) The Plural Actor. Cambridge:Polity Press.

Lehmann W (2009) Becoming Middle Class: How Working-class University Students Draw and Transgress Moral Class Boundaries. Sociology 43 (4): 631-647.

Lehmann W (2013) Habitus Transformation and Hidden Injuries. Sociology of Education XX(X): 115.

Modood T (2007) Multiculturalism. Cambridge UK \& Malden USA: Polity Press.

Noble G (2013) 'It is home but it not home': habitus, field and the migrant. Journal of Sociology 49:341-356.

Jenkins R (2002) Pierre Bourdieu. London \& New York: Routledge.

Jones G (2009) Youth. London: Sage. 
Parekh B (2000) The Future of Multi Ethnic Britain: The Parekh Report London Commission on the Future of Multi-Ethnic Britain. London: Runnymede Trust.

Peace Direct (2006) Young Muslims Speak. London: Peace Direct.

Ramji H (2007) Dynamics of Religion and Gender amongst Young British Muslims. Sociology 41(6): 1171-1189.

Reay D, Crozier G and Clayton J (2009) Strangers in Paradise? Working-class Students in Elite Universities. Sociology 43(6): 1103-1121.

Szydlik M (2008) Intergenerational Solidarity and Conflict. Journal of Comparative Family Studies 39(1): 97-114

Tarlo E (2010) Visibly Muslim: Fashion, Politics, Faith. Oxford: Berg.

The Qur'an English translation and introduction by T. Khalid (2008). Suffolk: Penguin Books.

Weigert A J and DW Teitge (1986) Society and Identity. Cambridge: Cambridge University Press.

Zine J (2001) Muslim youth in Canadian schools: education and the politics of religious identity. Antropology and Education Quartely 32(4): 399-423. 